\title{
Mixed 0-1 Goal Programming Approach TO INTERVAL-VALUED BILEVEL Programming Problems Via BIO-INSPIRED COMPUTATIONAL AlgORITHM
}

\author{
Debjani Chakraborti $^{1}$ and Papun Biswas ${ }^{2}$ \\ ${ }^{1}$ Department of Mathematics, Narula Institute of Technology, Kolkata, W.B, \\ India \\ debjani_333@yahoo.co.in \\ ${ }^{2}$ Department of Electrical Engineering, JIS College of Engineering, Kalyani, \\ W.B, India \\ papunbiswas@yahoo.com
}

\begin{abstract}
This paper presents how the mixed 0-1 programming in the framework of goal programming (GP) can be used to solve interval-valued fractional bilevel programming (IVFBLP) problems by employing genetic algorithm (GA) in a hierarchical decision making system. In the model formulation of the problem, a goal achievement function for minimizing the lower-bounds of the necessary regret intervals defined for the target intervals of achieving the goals and thereby arriving at a compromise decision is constructed by using both the aspects of 'minsum' and 'minmax' approaches in GP. In the decision process, an GA scheme is employed for execution of the problems at the two stages, target interval specification and optimal decision determination, for distribution of decision powers to the decision makers (DMs) in the order of hierarchy. A numerical example is provided to illustrate the potential use of the approach.
\end{abstract}

\section{KEYWORDS}

Fractional bilevel programming, Goal programming, Genetic algorithm, Interval-valued GP, Mixed 0-1 programming.

\section{INTRODUCTION}

The bilevel programming (BLP) approaches to hierarchical decision problems have been studied widely since Candler and Townsley [4] demonstrated the use of BLP to large hierarchical decision making and planning organizations.

In a BLP problem (BLPP), the two DMs located at the two different hierarchical levels control a vector of decision variables and each is interested in optimizing his/ her own benefit in the decision making horizon. Here, in actual practice, it has been realized that the cooperation between the DMs and a motivation to sacrifice the individual decision are needed for survival and sustainable growth of an organization.

In such a context, BLPPs as well as multilevel programming problems (MLPPs) as an extension of BLPPs have been studied [2, 3, 5, 8, and 22] deeply in the past. The fuzzy programming (FP) approaches $[7,19]$ to decentralized hierarchical decision problems have also been investigated 
from the point of view of potential use to different real-life decision problem like traffic control, economic system, warfare, network design, conflict resolution, and others.

The GAs $[9,17]$ as prominent tools to optimization of multiobjective decision making (MODM) problems $[15,16]$ have also been introduced to solve BLPPs $[12,18]$. The GA based fuzzy goal programming (FGP) approaches [20,24] to linear as well fractional BLPPs and MLPPs have been studied by Pal et al. [29, 30] in the recent past. However, the extensive study in this area is at an early stage.

Now, in most of the real-life decision situations, it is to be observed that, although the FP as well FGP as an extension of conventional GP [1] have been successfully implemented to different areas in the field of MODM, the DMs are often faced with the problem of assigning fuzzy aspiration levels to the objectives due to highly ambiguous in nature of them regarding achievement of their targets in an inexact decision making environment.

To overcome the above difficulty, interval programming (IP) approaches [10] have appeared as a prominent tool for solving decision problems with interval parameter values. The methodological aspects of IP studied in the past have been surveyed by Olivera et al. [25] in 2007. The methodological aspect of IP has also been studied by Pal et al. [26, 27] in the past. The GA based approach to IP problems with fractional criteria has been reported in [26] in the past. The potential use of IP to a real-life problem has also been investigated by Pal et al. [31] in the recent past.

However, methodological extension of IP is still at an early stage. Further, the use of an IP approach to hierarchical decision problems is yet to circulate in the literature.

In this article, a fractional bilevel programming problem having the characteristics of IP with interval coefficients in the objectives of both the DMs is considered. In the GP model formulation of the problem, the target intervals of the objectives of the DMs as well the control vector of the upper-level DM (the leader) are determined first by defining the best and worst objective values of the leader and the lower-level DM (the follower) with the use of an GA scheme. The intervalvalued objectives of the DMs and the control vector of the leader are then transformed into the standard goals in GP by using the notion of interval arithmetic technique in IP. In the goal achievement function, minimization of both the under- and over-deviational variables associated with the aspired goal levels under the framework of both the minsum [11] and minmax [1] approaches in GP is taken into consideration for minimizing the necessary lower-bounds of the regret intervals defined for the target intervals from the optimistic point of view of arriving at a compromise decision for both the DMs and overall benefit of the organization.

In the solution process, the formulated model is transformed into a mixed 0-1 GP formulation to overcome the combinatorial hard in nature of the executable problem. The proposed GA scheme is finally employed to reach a satisfactory decision on the basis of the weights of importance of achieving the goals.

The potential use of the approach is illustrated by a numerical example.

Now, formulation of the IVFBLP problem is presented in the following Section 2.

\section{Problem Formulation}

Let $\mathrm{X}=\left(\mathrm{x}_{1}, \mathrm{x}_{2}, \ldots, \mathrm{x}_{\mathrm{n}}\right)$ be the vector of decision variables involved with the two hierarchical decision systems. Then, let $F_{k}$ and $X_{k}$ be the objective function and the decision vector, respectively, of the k-th objective $\mathrm{F}_{\mathrm{k}}, \mathrm{k}=1,2$; where $\bigcup_{\mathrm{k}}\left\{\mathrm{X}_{\mathrm{k}} \mid \mathrm{k}=1,2\right\}=\mathrm{X}$. 
Then, the fractional BLPP with interval coefficients in a hierarchical decision structure can be presented as:

Find $\mathrm{X}\left(\mathrm{X}_{1}, \mathrm{X}_{2}\right)$ so as to:

$$
\operatorname{Max}_{\mathrm{X}_{1}} \mathrm{~F}_{1}\left(\mathrm{X}_{1}, \mathrm{X}_{2}\right)=\frac{\left[\mathrm{c}_{11}^{\mathrm{L}}, \mathrm{c}_{11}^{\mathrm{U}}\right] \mathrm{X}_{1}+\left[\mathrm{c}_{12}^{\mathrm{L}}, \mathrm{c}_{\mathrm{U}}^{\mathrm{U}}\right] \mathrm{X}_{2}+\left[\alpha_{1}^{\mathrm{L}}, \alpha_{1}^{\mathrm{U}}\right]}{\left[\mathrm{d}_{11}^{\mathrm{L}}, \mathrm{d}_{11}^{\mathrm{U}}\right] \mathrm{X}_{1}+\left[\mathrm{d}_{12}^{\mathrm{L}}, \mathrm{d}_{12}^{\mathrm{U}}\right] \mathrm{X}_{2}+\left[\beta_{1}^{\mathrm{L}}, \beta_{1}^{\mathrm{U}}\right]} \quad \text { (Leader's problem) }
$$

and, for given $\mathrm{X}_{1}, \mathrm{X}_{2}$ solves

$$
\operatorname{Max}_{\mathrm{X}_{2}} \mathrm{~F}_{2}\left(\mathrm{X}_{1}, \mathrm{X}_{2}\right)=\frac{\left[\mathrm{[c}_{21}^{\mathrm{L}}, \mathrm{c}_{21}^{\mathrm{U}}\right] \mathrm{X}_{1}+\left[\mathrm{c}_{22}^{\mathrm{L}}, \mathrm{c}_{22}^{\mathrm{U}}\right] \mathrm{X}_{2}+\left[\alpha_{2}^{\mathrm{L}}, \alpha_{2}^{\mathrm{U}}\right]}{\left[\mathrm{d}_{21}^{\mathrm{L}}, \mathrm{d}_{21}^{\mathrm{U}}\right] \mathrm{X}_{1}+\left[\mathrm{d}_{22}^{\mathrm{L}}, \mathrm{d}_{22}^{\mathrm{U}}\right] \mathrm{X}_{2}+\left[\beta_{2}^{\mathrm{L}}, \beta_{2}^{\mathrm{U}}\right]} \quad \text { (Follower's problem) }
$$

subject to,

$$
\mathrm{X} \in \mathrm{S}=\left\{\left(\mathrm{X}_{1}, \mathrm{X}_{2}\right) \mid \mathrm{A}_{1} \mathrm{X}_{1}+\mathrm{A}_{2} \mathrm{X}_{2}\left(\begin{array}{l}
\geq \\
\leq
\end{array}\right) \mathrm{b}, \mathrm{X} \geq 0\right\},
$$

where $\mathrm{x} \in \mathrm{R}^{\mathrm{n}}, \mathrm{b} \in \mathrm{R}^{\mathrm{m}}$, and $\left[\mathrm{c}_{\mathrm{k} \ell}^{\mathrm{L}}, \mathrm{c}_{\mathrm{k} \ell}^{\mathrm{U}}\right],\left[\mathrm{d}_{\mathrm{k} \ell}^{\mathrm{L}}, \mathrm{d}_{\mathrm{k} \ell}^{\mathrm{U}}\right] \quad(\mathrm{k}, \ell=1,2)$ are the interval coefficient vectors, $\alpha_{\mathrm{k}}^{\mathrm{L}}, \alpha_{\mathrm{k}}^{\mathrm{U}}, \beta_{\mathrm{k}}^{\mathrm{L}}, \beta_{\mathrm{k}}^{\mathrm{U}},(\mathrm{k}=1,2)$ are constants, $\mathrm{L}$ and $\mathrm{U}$ stands for the lower and upper bounds, respectively, of the defined intervals. $\mathrm{A}_{1}$ and $\mathrm{A}_{2}$ are constant matrices and $\mathrm{b}$ is a constant vector. It is assumed that the feasible region $\mathrm{S}(\neq \Phi)$ is a convex set.

Again, it is customary to assume that $\left[\mathrm{d}_{\mathrm{k} 1}^{\mathrm{L}}, \mathrm{d}_{\mathrm{k} 1}^{\mathrm{U}}\right] \mathrm{X}_{1}+\left[\mathrm{d}_{\mathrm{k} 2}^{\mathrm{L}}, \mathrm{d}_{\mathrm{k} 2}^{\mathrm{U}}\right] \mathrm{X}_{2}+\left[\beta_{\mathrm{k}}^{\mathrm{L}}, \beta_{\mathrm{k}}^{\mathrm{U}}\right]>0$.

Now, using the interval arithmetic operation rule [14], the interval-valued objectives in (1) and (2) can be successively expressed as [27]:

$$
\begin{aligned}
& \operatorname{MaxF}_{\mathrm{X}_{1}}\left(\mathrm{X}_{1}, \mathrm{X}_{2}\right)=\left[\frac{\mathrm{c}_{11}^{\mathrm{L}} \mathrm{X}_{1}+c_{12}^{\mathrm{L}} \mathrm{X}_{2}+\alpha_{1}^{\mathrm{L}}}{\mathrm{d}_{11}^{\mathrm{U}} \mathrm{X}_{1}+\mathrm{d}_{12}^{\mathrm{U}} \mathrm{X}_{2}+\beta_{1}^{\mathrm{U}}}, \frac{c_{11}^{\mathrm{U}} \mathrm{X}_{1}+c_{12}^{\mathrm{U}} \mathrm{X}_{2}+\alpha_{1}^{\mathrm{U}}}{\mathrm{d}_{11}^{\mathrm{L}} \mathrm{X}_{1}+\mathrm{d}_{12}^{\mathrm{L}} \mathrm{X}_{2}+\beta_{1}^{\mathrm{L}}}\right]=\left[\mathrm{T}_{1 \mathrm{~L}}\left(\mathrm{X}_{1}, \mathrm{X}_{2}\right), \mathrm{T}_{1 \mathrm{U}}\left(\mathrm{X}_{1}, \mathrm{X}_{2}\right)\right] \text {, (say) } \\
& \operatorname{Max}_{X_{2}}\left(X_{1}, X_{2}\right)=\left[\frac{c_{21}^{L} X_{1}+c_{22}^{L} X_{2}+\alpha_{2}^{L}}{d_{21}^{\mathrm{U}} X_{1}+d_{22}^{U} X_{2}+\beta_{2}^{U}}, \frac{c_{21}^{U} X_{1}+c_{22}^{U} X_{2}+\alpha_{2}^{U}}{d_{21}^{L} X_{1}+d_{22}^{L} X_{2}+\beta_{2}^{L}}\right]=\left[T_{2 L}\left(X_{1}, X_{2}\right), T_{2 U}\left(X_{1}, X_{2}\right)\right], \text { (say) }
\end{aligned}
$$

Now, to determine the target intervals of the expressions in (4) and (5) and thereby formulating the GP model of the problem, an GA scheme adopted in the solution search process is presented in the Section 3.

\section{DESIGN OF GA SCHEME}

The two major operational activities in a GA approach are selection and crossover. In the present GA search process, the fitter Codon selection [23] and two-point crossover [9] used is defined as follows:

(i) fitter Codon selection:

The cordons are parts of a binary coded chromosome in a population. In a conventional GA method to optimization problems in [9, 13, 17], Roulette-wheel scheme studied in [9] is used for selection of parents. In the fitter Codon selection scheme in $[23,28]$ a comparison of the selected strings with the given string lengths are used to determine the fitter one. In the present GA approach, the cordons selection is made by considering the portion of a string from its most significant bit to the bit position with a specified length. In such a selection scheme, the consideration of full string length of a chromosome as well as conversion to its binary value is not 
required in the selection process. This process substantially reduces the computational load in the selection search process.

(ii) two-point crossover:

In the conventional GA approach [13] single-point crossover is considered. In the present GA scheme, two-point crossover in [9] is considered. The merit of choosing this type of operation is that a completely new population from the initial population is generated in a less number of iterations in contrast to the single-point crossover.

The algorithmic steps of the GA method are presented in the following Section 3.1

\subsection{Steps of the Proposed GA}

\section{Step 1. Representation and Initialization}

Let $V_{P}$ denotes the binary coded representation of chromosome in a population as

$V_{P}=\left\{\mathrm{x}_{1}, \mathrm{x}_{2}, \ldots, \mathrm{x}_{\mathrm{n}}\right\}_{P}$, where 'n' denotes the length of a chromosome, and $\mathrm{P}=1,2, \ldots$, pop_size, represents the population size, and where pop_size chromosomes are randomly initialized in its search domain.

\section{Step 2. Fitness function}

The fitness value of each chromosome is determined by the value of an objective function. The fitness function is defined as:

$$
\text { eval }\left(V_{\mathrm{P}}\right)=\left(\mathrm{F}_{\mathrm{K}}\right)_{\mathrm{P}}, \quad \mathrm{k}=1,2 ; \mathrm{P}=1,2, \ldots, \text { pop_size. }
$$

The best chromosome for the best and least value of the objective function is determined as:

$$
\begin{gathered}
V^{*}=\max \left\{\operatorname{eval}\left(V_{P}\right) \mid \mathrm{P}=1,2, \text { pop_size }\right\}, \\
\text { And } V^{*}=\min \left\{\operatorname{eval}\left(V_{P}\right) \mid \mathrm{P}=1,2, \text { pop_size }\right\} \text {, respectively. }
\end{gathered}
$$

\section{Step 3. Selection}

The fitter Codon selection scheme is used in the proposed GA. Here, chromosomes are likely to be selected from the population depending on their fitness score. The merit of the fitter Codon selection is to reach a solution with predefined level of fitness.

For instance, the following four chromosomes in a population are considered.

(i) $\quad \underline{111010} 000$

(ii) $\underline{111101010}$

(iii) 010111010

(iv) $\quad 101010010$

Here, cordons are selected from the stand point of maximum occurrence of dominant values of the most significant bits, where Codon length is defined by the number of bits from most significant bit position bit to the position of first non-matching bit in the selected pair. It is observed here that the chromosomes in (i) and (ii) are the fitter with Codon length 4 in 
comparison to the others in (iii) and (iv). Again, it is to be followed that the chromosome in (ii) is fitter than the chromosome in (i). It is clear from the above that the decimal equivalents of chromosomes are not required here for selection of one with better fitness score. The merit of the use of this selection scheme to different problems has been studied [29] in the recent past.

\section{Step 4. Crossover}

The probability of crossover is defined by the parameter $\mathrm{P}_{\mathrm{c}}$. Here in a two-point crossover genetic system, the mating chromosomes interchange their middle portion in the process of reproduction. Again, a chromosome is selected as a parent, if for two defined random number $r, r_{1} \in[0,1] ; r$, $\mathrm{r}_{1}<\mathrm{P}_{\mathrm{c}}$ with $\mathrm{r}+\mathrm{r}_{1}<1$ is satisfied.

In the selection of two parents, another random number $r_{2}$ is defined such that $r_{2}=1-r-r_{1}$. Then, two parents $V_{1}, V_{2} \in \mathrm{S}$ yield two offspring as:

$\mathrm{V}_{1}^{1}=\left(\mathrm{r}+\mathrm{r}_{2}\right) \cdot V_{1}+\mathrm{r}_{1} V_{2}, \quad \mathrm{~V}_{2}^{1}=\mathrm{r}_{1} \cdot \mathrm{V}_{1}+\left(\mathrm{r}+\mathrm{r}_{2}\right) \cdot V_{2}$, where $\mathrm{V}_{1}^{1}, \mathrm{~V}_{2}^{1} \in \mathrm{S}$

\section{Step 5. Mutation}

The parameter $\mathrm{P}_{\mathrm{m}}$ is conventionally defined as the probability of mutation. The mutation operation is performed on a bit-by-bit basis, where for a random number $\mathrm{r} \in[0,1]$, a chromosome is selected for mutation provided that $\mathrm{r}<\mathrm{P}_{\mathrm{m}}$.

\section{Step 6. Termination}

The execution process terminates when the generated best chromosome is reported after a certain number of generations as the decision in the genetic search process.

Now, formulation of the interval-valued goals of the problem is presented in the Section 4.

\section{INTERVAL-VALUED GOAL FORMULATION}

To formulate the GP model of the BLPP, the target intervals for both the objectives $F_{1}$ and $F_{2}$ and the decision vector $\mathrm{X}_{1}$ controlled by the leader are to be defined in the decision making environment.

\subsection{Determination of Target Interval}

To determine the target intervals, the best and worst solutions of the objectives are to be determined first, and that can be obtained using the GA scheme by defining the parameter values of it.

Let the individual best and least solutions of the leader be

$$
\begin{aligned}
& \left(\mathrm{X}_{1}^{\ell \mathrm{b}}, \mathrm{X}_{2}^{\ell \mathrm{b}} ; \mathrm{T}_{1 \mathrm{U}}^{*}\right) \text { and }\left(\mathrm{X}_{1}^{\ell \mathrm{w}}, \mathrm{X}_{2}^{\ell \mathrm{w}} ; \mathrm{T}_{1 \mathrm{~L}}^{*}\right) \text {, respectively, } \\
& \text { where } \mathrm{T}_{1 \mathrm{U}}^{*}=\operatorname{Max}_{\left(\mathrm{X}_{1}, \mathrm{X}_{2}\right) \in \mathrm{S}} \mathrm{T}_{1 \mathrm{U}}\left(\mathrm{X}_{1}, \mathrm{X}_{2}\right), \\
& \text { and } \mathrm{T}_{1 \mathrm{~L}}^{*}=\operatorname{Min}_{\left(\mathrm{X}_{1}, \mathrm{X}_{2}\right) \in \mathrm{S}} \mathrm{T}_{1 \mathrm{~L}}\left(\mathrm{X}_{1}, \mathrm{X}_{2}\right) .
\end{aligned}
$$


Similarly, the individual best and worst solutions of the follower can be obtained as

$\left(\mathrm{X}_{1}^{\mathrm{fb}}, \mathrm{X}_{2}^{\mathrm{fb}} ; \mathrm{T}_{2 \mathrm{U}}^{*}\right)$ and $\left(\mathrm{X}_{1}^{\mathrm{fw}}, \mathrm{X}_{2}^{\mathrm{fw}} ; \mathrm{T}_{2 \mathrm{~L}}^{*}\right)$, respectively,

Where $\mathrm{T}_{2 \mathrm{U}}^{*}=\operatorname{Max}_{\left(\mathrm{X}_{1}, \mathrm{X}_{2}\right) \in \mathrm{S}} \mathrm{T}_{2 \mathrm{U}}\left(\mathrm{X}_{1}, \mathrm{X}_{2}\right)$,

And $\quad \mathrm{T}_{2 \mathrm{~L}}^{*}=\operatorname{Min}_{\left(\mathrm{X}_{1}, \mathrm{X}_{2}\right) \in \mathrm{S}} \mathrm{T}_{2 \mathrm{~L}}\left(\mathrm{X}_{1}, \mathrm{X}_{2}\right)$.

Now, in the decision making context, it is reasonably assumed that both the leader and follower are motivated to cooperate each other and each is willing to sacrifice his/ her own benefit up to a certain level for a gain of the other from the view point of survival as well as sustainable growth of the organization.

From the above view point, the target intervals of the objective $F_{k}$ can be determined as:

$$
\left[\mathrm{t}_{\mathrm{k}}^{\mathrm{L}}, \mathrm{t}_{\mathrm{k}}^{\mathrm{U}}\right], \mathrm{k}=1,2
$$

Where $\mathrm{T}_{\mathrm{kL}}^{*} \leq \mathrm{t}_{\mathrm{k}}^{\mathrm{L}} \leq \mathrm{t}_{\mathrm{k}}^{\mathrm{U}} \leq \mathrm{T}_{\mathrm{kU}}^{*}, \mathrm{k}=1,2$, and the consideration of which depends on the decision making situation.

Then, the expressions in (4) and (5) with the target intervals can be presented as:

$$
\begin{aligned}
& {\left[\mathrm{T}_{1 \mathrm{~L}}\left(\mathrm{X}_{1}, \mathrm{X}_{2}\right), \mathrm{T}_{1 \mathrm{U}}\left(\mathrm{X}_{1}, \mathrm{X}_{2}\right)\right]=\left[\mathrm{t}_{1}^{\mathrm{L}}, \mathrm{t}_{1}^{\mathrm{U}}\right],(\text { Leader's problem) }} \\
& {\left[\mathrm{T}_{2 \mathrm{~L}}\left(\mathrm{X}_{1}, \mathrm{X}_{2}\right), \mathrm{T}_{2 \mathrm{U}}\left(\mathrm{X}_{1}, \mathrm{X}_{2}\right)\right]=\left[\mathrm{t}_{2}^{\mathrm{L}}, \mathrm{t}_{2}^{\mathrm{U}}\right] \text { (Follower's problem) }}
\end{aligned}
$$

Again, since the leader has a higher power of making decision, relaxation on the best decision $\mathrm{X}_{1}^{\mathrm{lb}}$ up to a certain level as the lower tolerance limit should be considered by the leader for searching of a better decision by the follower. Let $\mathrm{X}_{1}^{l}\left(\mathrm{X}_{1}^{l \mathrm{w}}<\mathrm{X}_{1}^{l}<\mathrm{X}_{1}^{l \mathrm{~b}}\right)$ be the lower tolerance limit of the decision vector $\mathrm{X}_{1}$ controlled by the leader.

Now, using the concept of mid-point arithmetic of IP [14] the interval objective of the control vector $\mathrm{X}_{1}$ can be obtained as:

$$
\mathrm{X}_{1}=\left[\mathrm{X}_{1}^{\mathrm{l}}, \mathrm{X}_{1}^{\mathrm{lb}}\right]
$$

Now, the standard goal representation of the defined objectives in the GP formulation is discussed in the following Section 4.2.

\subsection{Standard Goal Representation of Interval-Valued Goal}

To formulate the GP model of the problem, the objectives in (6), (7) and (8) are to be transformed into the standard goals by introducing the target intervals and the under- and over- deviational variables to each of them.

The standard goal expressions of the objectives are successively obtained as

$$
\mathrm{T}_{\mathrm{IL}}\left(\mathrm{X}_{1}, \mathrm{X}_{2}\right)+\mathrm{d}_{\mathrm{lL}}^{-}-\mathrm{d}_{\mathrm{IL}}^{+}=\mathrm{t}_{1}^{\mathrm{L}} \text {, }
$$


and $\mathrm{T}_{1 \mathrm{U}}\left(\mathrm{X}_{1}, \mathrm{X}_{2}\right)+\mathrm{d}_{1 \mathrm{U}}^{-}-\mathrm{d}_{1 \mathrm{U}}^{+}=\mathrm{t}_{1}^{\mathrm{U}} ; \quad$ (Leader's problem)

$\mathrm{T}_{2 \mathrm{~L}}\left(\mathrm{X}_{1}, \mathrm{X}_{2}\right)+\mathrm{d}_{2 \mathrm{~L}}^{-}-\mathrm{d}_{2 \mathrm{~L}}^{+}=\mathrm{t}_{2}^{\mathrm{L}}$,

and $\mathrm{T}_{2 \mathrm{U}}\left(\mathrm{X}_{1}, \mathrm{X}_{2}\right)+\mathrm{d}_{2 \mathrm{U}}^{-}-\mathrm{d}_{2 \mathrm{U}}^{+}=\mathrm{t}_{2}^{\mathrm{U}}$, (Follower's problem)

Where $\left(\mathrm{d}_{\mathrm{kL}}^{-}, \mathrm{d}_{\mathrm{kU}}^{-}\right) \geq 0, \mathrm{k}=1,2$ represent under-deviational variables and $\left(\mathrm{d}_{\mathrm{kL}}^{+}, \mathrm{d}_{\mathrm{kU}}^{+}\right) \geq 0, \mathrm{k}=1,2$ represent over-deviational variables, respectively, associated with the respective goal expressions. Again, the goal expressions for the control vector $\mathrm{X}_{1}$ are obtained as:

$\mathrm{X}_{1}+\mathrm{d}_{\mathrm{L}}^{-}-\mathrm{d}_{\mathrm{L}}^{+}=\mathrm{X}_{1}^{\ell}$,

And $\mathrm{X}_{1}+\mathrm{d}_{\mathrm{U}}^{-}-\mathrm{d}_{\mathrm{U}}^{+}=\mathrm{X}_{1}^{\imath \mathrm{b}}$.

Where, $\left(\mathrm{d}_{\mathrm{L}}^{-}, \mathrm{d}_{\mathrm{L}}^{+}\right)$and $\left(\mathrm{d}_{\mathrm{U}}^{-}, \mathrm{d}_{\mathrm{U}}^{+}\right) \geq 0$ represent the vectors of under- and over- deviational variables, respectively, and where the dimension of each of them depends on $\mathrm{X}_{1}$.

Now, formulation of the GP model of the problem is presented in the Section 5.

\section{GP MODEL FORMULATION}

In a decision making situation, the aim of each of the DMs, is to achieve the goal values within the specified ranges by means of minimizing the necessary regrets in terms of the deviational variables involved in the decision situation.

In the present decision situation, the goal achievement function is termed as the regret function, since the regret intervals defined for goal achievement within the specified target intervals are to be minimized to the extent possible in the decision making environment.

Now, in the field of interval programming, both the aspects of GP, minsum GP [11] for minimizing the sum of the weighted unwanted deviational variables as well as minmax GP [1] for minimizing the maximum of the deviations, are simultaneously taken into account as a convex combination of them to reach a satisfactory solution within the specified target intervals of the goals.

Here, from the optimistic point of view of both the DMs, minimization of the necessary regrets involved with the regret intervals $\left(\mathrm{d}_{\mathrm{kL}}^{-}, \mathrm{d}_{\mathrm{kU}}^{+}\right),\left(\mathrm{d}_{\mathrm{kL}}^{+}, \mathrm{d}_{\mathrm{kU}}^{-}\right),(\mathrm{k}=1,2)$, and $\left(\mathrm{d}_{\mathrm{L}}^{-}, \mathrm{d}_{\mathrm{U}}^{+}\right),\left(\mathrm{d}_{\mathrm{L}}^{+}, \mathrm{d}_{\mathrm{U}}^{-}\right)$are taken into consideration.

Now, for model simplification let it is assumed that $n_{1}\left(n_{1}<n\right)$ be the number of decision variables involved with the control vector $\mathrm{X}_{1}$.

Then, the GP model of the problem under consideration takes the form:

Find $\mathrm{X}\left(\mathrm{X}_{1}, \mathrm{X}_{2}\right)$ so as to

Minimize $\mathrm{Z}=$

$$
\lambda\left\{\sum_{\mathrm{i}=1}^{\mathrm{n}_{1}+2}\left(\mathrm{w}_{\mathrm{iL}}^{-} \mathrm{d}_{\mathrm{iL}}^{-}+\mathrm{w}_{\mathrm{iU}}^{+} \mathrm{d}_{\mathrm{iU}}^{+}\right) \wedge \sum_{\mathrm{i}=1}^{\mathrm{n}_{1}+2}\left(\mathrm{w}_{\mathrm{iL}}^{+} \mathrm{d}_{\mathrm{iL}}^{+}+\mathrm{w}_{\mathrm{iU}}^{-} \mathrm{d}_{\mathrm{iU}}^{-}\right)\right\}+(1-\lambda)\left\{\max _{\mathrm{i} \in \mathrm{n}_{1}+2}\left\{\mathrm{~d}_{\mathrm{iL}}^{-}+\mathrm{d}_{\mathrm{iU}}^{+}\right\} \wedge\left(\mathrm{d}_{\mathrm{iL}}^{+}+\mathrm{d}_{\mathrm{iU}}^{-}\right)\right\}
$$


and satisfy the goal constraints defined in (9) - (14), subject to the system constraint in (3), where $\mathrm{Z}$ represents the regret function for goal achievement; $\mathrm{d}_{\mathrm{iL}}^{-}, \mathrm{d}_{\mathrm{iU}}^{+}, \mathrm{d}_{\mathrm{iL}}^{+}, \mathrm{d}_{\mathrm{iU}}^{-}\left(\mathrm{i}=1,2, \ldots,\left(\mathrm{n}_{1}+2\right)\right)$, are successively renamed for $\mathrm{d}_{\mathrm{kL}}^{-}, \mathrm{d}_{\mathrm{kU}}^{+}, \mathrm{d}_{\mathrm{kL}}^{+}, \mathrm{d}_{\mathrm{kU}}^{-}(\mathrm{k}=1,2)$, and $\mathrm{n}_{1}$ components of each of the $\mathrm{d}_{\mathrm{L}}^{-}, \mathrm{d}_{\mathrm{U}}^{+}, \mathrm{d}_{\mathrm{L}}^{+}, \mathrm{d}_{\mathrm{U}}^{-}$, and where $\left(\mathrm{w}_{\mathrm{iL}}^{-}, \mathrm{w}_{\mathrm{iU}}^{+}, \mathrm{w}_{\mathrm{iL}}^{+}, \mathrm{w}_{\mathrm{iU}}^{-}\right)>0$ with $\sum_{\mathrm{i}}\left(\mathrm{w}_{\mathrm{iL}}^{-}+\mathrm{w}_{\mathrm{iU}}^{+}+\mathrm{w}_{\mathrm{iL}}^{+}+\mathrm{w}_{\mathrm{iU}}^{-}\right)=1$ denote the numerical weights of importance of achieving the goals within the respective target intervals, and $0<\lambda<1 ; \wedge$ stands for min operator.

Now, it is to be followed that the function $\mathrm{Z}$ in (15) is non-convex in nature in the field of combinational optimization.

The mixed 0-1 programming technique as the most widely used [10] and the simplest version of solving such problems is introduced here to solve the problem.

\subsection{Mixed 0-1 Programming to GP Model}

Introducing the variable $z_{i} \in\{0,1\}$, (either 0 or 1$),\left(\mathrm{k}=1,2, \ldots,\left(\mathrm{n}_{1}+2\right)\right)$ the regret function $\mathrm{Z}$ in (15) can be recast as:

Minimize $\mathrm{Z}=\lambda\left\{\sum_{\mathrm{i}=1}^{\mathrm{n}_{1}+2}\left(\mathrm{w}_{\mathrm{iL}}^{-} \mathrm{d}_{\mathrm{iL}}^{-}+\mathrm{w}_{\mathrm{iU}}^{+} \mathrm{d}_{\mathrm{iU}}^{+}\right) \mathrm{z}_{\mathrm{i}}+\sum_{\mathrm{i}=1}^{\mathrm{n}_{1}+2}\left(\mathrm{w}_{\mathrm{iL}}^{+} \mathrm{d}_{\mathrm{iL}}^{+}+\mathrm{w}_{\mathrm{iU}}^{-} \mathrm{d}_{\mathrm{iU}}^{-}\right)\left(1-\mathrm{z}_{\mathrm{i}}\right)\right\}+(1-\lambda) \mathrm{V}$,

Where

$\left\{\max _{i \in \mathrm{n}_{1}+2}\left\{\left(\mathrm{~d}_{\mathrm{iL}}^{-}+\mathrm{d}_{\mathrm{iU}}^{+}\right) \wedge\left(\mathrm{d}_{\mathrm{iL}}^{+}+\mathrm{d}_{\mathrm{iU}}^{-}\right)\right\}\right\}=\mathrm{V}$

Now, the expression in (17) in general format can be represented as:

$\left(\mathrm{d}_{\mathrm{iL}}^{-}+\mathrm{d}_{\mathrm{iU}}^{+}\right) \wedge\left(\mathrm{d}_{\mathrm{iL}}^{+}+\mathrm{d}_{\mathrm{iU}}^{-}\right) \leq \mathrm{V}, \mathrm{i}=1,2,\left(\mathrm{n}_{1}+2\right)$

Then, incorporating the variable $z_{i}$ defined above, the relational expression in (18) can be presented in its equivalent form as:

$\left(\mathrm{d}_{\mathrm{iL}}^{-}+\mathrm{d}_{\mathrm{iU}}^{+}\right) \mathrm{z}_{\mathrm{i}}+\left(\mathrm{d}_{\mathrm{iL}}^{+}+\mathrm{d}_{\mathrm{iU}}^{-}\right)\left(1-\mathrm{z}_{\mathrm{i}}\right) \leq \mathrm{V}$,

where $z_{i} \in\{0,1\} \quad ; \mathrm{i}=1,2, . .,\left(\mathrm{n}_{1}+2\right)$

Finally, the executable GP model appears as:

Minimize $\mathrm{Z}=\lambda\left\{\sum_{\mathrm{i}=1}^{\mathrm{n}_{1}+2}\left(\mathrm{w}_{\mathrm{iL}}^{-} \mathrm{d}_{\mathrm{iL}}^{-}+\mathrm{w}_{\mathrm{iU}}^{+} \mathrm{d}_{\mathrm{iU}}^{+}\right) \mathrm{z}_{\mathrm{i}}+\sum_{\mathrm{i}=1}^{\mathrm{n}_{1}+2}\left(\mathrm{w}_{\mathrm{iL}}^{+} \mathrm{d}_{\mathrm{iL}}^{+}+\mathrm{w}_{\mathrm{iU}}^{-} \mathrm{d}_{\mathrm{iU}}^{-}\right)\left(1-\mathrm{z}_{\mathrm{i}}\right)\right\}+(1-\lambda) \mathrm{V}$,

subject to the constraints sets defined in (15) and (19) Now, since GA is a goal satisfier [9] rather than optimizer, the defined GA scheme can be employed here to minimize the regret function ' $\mathrm{Z}$ ' in (20) and thereby to reach a satisfactory decision by minimizing the regrets of both the DMs.

Here, the fitness function appears as:

$$
\operatorname{Eval}\left(\mathrm{V}_{\mathrm{P}}\right)=(\mathrm{Z})_{\mathrm{P}}, \mathrm{P}=1,2 \text {, pop_size. }
$$

The best chromosome $\mathrm{V}^{*}$ with highest fitness score at a generation is determined as: 


$$
\mathrm{V}^{*}=\min \left\{\operatorname{eval}\left(\mathrm{V}_{\mathrm{P}}\right) \mid \mathrm{P}=1,2 \ldots, \text { pop_size }\right\} .
$$

To illustrate the proposed approach, a numerical example is solved.

\section{NUMERICAL EXAMPLE}

Let the two decision variables $\mathrm{x}_{1}$ and $\mathrm{x}_{2}$ are under the control of the leader and follower, respectively.

Then, the FBLPP with interval coefficients can be presented as:

Find $\mathrm{X}\left(\mathrm{x}_{1}, \mathrm{x}_{2}\right)$ so as to

$$
\underset{\mathrm{x}_{1}}{\operatorname{Max}} \mathrm{F}_{1}\left(\mathrm{x}_{1}, \mathrm{x}_{2}\right)=\frac{[1,2] \mathrm{x}_{1}+[5,11] \mathrm{x}_{2}+[7,8]}{[4,5] \mathrm{x}_{1}+[3,7] \mathrm{x}_{2}+[3,3]}, \text { (Leader's problem) }
$$

And, for given $\mathrm{x}_{1}, \mathrm{x}_{2}$ solves

$$
\underset{x_{2}}{\operatorname{Max}} F_{2}\left(x_{1}, x_{2}\right)=\frac{[3,4] x_{1}+[1,2] x_{2}}{[6,7] x_{1}+[2,4] x_{2}+[5,6]},(\text { Follower's problem) }
$$

subject to

$\mathrm{x}_{1}+\mathrm{x}_{2} \leq 6, \quad-\mathrm{x}_{1}+\mathrm{x}_{2} \leq 3$,

$x_{1}+2 x_{2} \geq 2, \quad x_{1} \leq 4$,

$\mathrm{x}_{1}, \mathrm{x}_{2} \geq 0$.

Now, following the procedure, the Leader's objective in interval form appear as

$$
\left(\frac{x_{1}+5 x_{2}+7}{5 x_{1}+7 x_{2}+3}, \frac{2 x_{1}+11 x_{2}+8}{4 x_{1}+3 x_{2}+3}\right),
$$

And that of the Follower takes the form:

$$
\left(\frac{3 x_{1}+x_{2}}{7 x_{1}+4 x_{2}+6}, \frac{4 x_{1}+2 x_{2}}{6 x_{1}+2 x_{2}+5}\right) \text {. }
$$

To solve the problem by employing the proposed GA scheme, the following genetic parameter values are found effective in the solution search process:

The probability of crossover $\mathrm{P}_{\mathrm{c}}=0.8$,

Probability of mutation $\mathrm{P}_{\mathrm{m}}=0.07$,

Population size $=100$,

Chromosome length $=30$.

The GA is implemented using the Programming Language C. The execution is done in an Intel Pentium IV with $2.66 \mathrm{GHz}$. Clock-pulse and $1 \mathrm{~GB}$ RAM.

The Leader's best and worst solutions are obtained as:

$$
\begin{aligned}
\left(\mathrm{X}_{1}^{l \mathrm{~b}}, \mathrm{X}_{2}^{l \mathrm{~b}} ; \mathrm{T}_{1 \mathrm{U}}^{*}\right) & =(0,3 ; 3.41) \\
\text { And }\left(\mathrm{X}_{1}^{l \mathrm{w}}, \mathrm{X}_{2}^{l \mathrm{w}} ; \mathrm{T}_{1 \mathrm{~L}}^{*}\right) & =(4,0 ; 0.47), \text { respectively. }
\end{aligned}
$$


The Follower's best and worst solutions are found as

$$
\left(\mathrm{X}_{1}^{\mathrm{fb}}, \mathrm{X}_{2}^{\mathrm{fb}} ; \mathrm{T}_{2 \mathrm{U}}^{*}\right)=(1.5,4.5 ; 0.65)
$$

and $\left(\mathrm{X}_{1}^{\mathrm{fw}}, \mathrm{X}_{2}^{\mathrm{fw}} ; \mathrm{T}_{2 \mathrm{~L}}^{*}\right)=(0,1 ; 0.1)$, respectively.

Now, following the procedure, the interval objectives with target intervals can be obtained as:

$$
\begin{aligned}
& \left(\frac{x_{1}+5 x_{2}+7}{5 x_{1}+7 x_{2}+3}, \frac{2 x_{1}+11 x_{2}+8}{4 x_{1}+3 x_{2}+3}\right)=[0.47,3.41], \text { (Leader's problem) } \\
& \left(\frac{3 x_{1}+x_{2}}{7 x_{1}+4 x_{2}+6}, \frac{4 x_{1}+2 x_{2}}{6 x_{1}+2 x_{2}+5}\right)=[0.1,0.65], \quad \text { (Follower's problem) }
\end{aligned}
$$

Again, the decision variable $\mathrm{x}_{1}$ with its target interval appears as:

$$
[1,1] \mathrm{x}_{1}=[0,1.5]
$$

Then, the goals in standard GP formulation are obtained as:

$$
\begin{array}{ll}
\frac{\mathrm{x}_{1}+5 \mathrm{x}_{2}+7}{5 \mathrm{x}_{1}+7 \mathrm{x}_{2}+3}+\mathrm{d}_{1 \mathrm{~L}}^{-}-\mathrm{d}_{1 \mathrm{~L}}^{+}=0.47, & \frac{2 \mathrm{x}_{1}+11 \mathrm{x}_{2}+8}{4 \mathrm{x}_{1}+3 \mathrm{x}_{2}+3}+\mathrm{d}_{1 \mathrm{U}}^{-}-\mathrm{d}_{1 \mathrm{U}}^{+}=3.41 \\
\frac{3 \mathrm{x}_{1}+\mathrm{x}_{2}}{7 \mathrm{x}_{1}+4 \mathrm{x}_{2}+6}+\mathrm{d}_{2 \mathrm{~L}}^{-}-\mathrm{d}_{2 \mathrm{~L}}^{+}=0.1, & \frac{4 \mathrm{x}_{1}+2 \mathrm{x}_{2}}{6 \mathrm{x}_{1}+2 \mathrm{x}_{2}+5}+\mathrm{d}_{2 \mathrm{U}}^{-}-\mathrm{d}_{2 \mathrm{U}}^{+}=0.65 \\
\mathrm{x}_{1}+\mathrm{d}_{3 \mathrm{~L}}^{-}-\mathrm{d}_{3 \mathrm{~L}}^{+}=0, \quad \mathrm{x}_{1}+\mathrm{d}_{3 \mathrm{U}}^{-}-\mathrm{d}_{3 \mathrm{U}}^{+}=1.5
\end{array}
$$

Using the expressions of $\mathrm{Z}$ in (20) and following the procedure, the executable GP model in the form of mixed 0-1 programming problem appears as:

Find $\mathrm{X}\left(\mathrm{x}_{1}, \mathrm{x}_{2}\right)$ so as to

Minimize $\mathrm{Z}=\lambda\left\{\sum_{\mathrm{i}=1}^{3}\left\{\left(\mathrm{w}_{\mathrm{iL}}^{-} \mathrm{d}_{\mathrm{iL}}^{-}+\mathrm{w}_{\mathrm{iU}}^{+} \mathrm{d}_{\mathrm{iU}}^{+}\right) \mathrm{z}_{\mathrm{i}}+\left(\mathrm{w}_{\mathrm{iL}}^{+} \mathrm{d}_{\mathrm{iL}}^{+}+\mathrm{w}_{\mathrm{iU}}^{-} \mathrm{d}_{\mathrm{iU}}^{-}\right)\left(1-\mathrm{z}_{\mathrm{i}}\right)\right\}\right\}+(1-\lambda) \mathrm{V}$,

And satisfy the goal expressions in (24)

subject to, $\left(\mathrm{d}_{\mathrm{iL}}^{-}+\mathrm{d}_{\mathrm{iU}}^{+}\right) \mathrm{z}_{\mathrm{i}}+\left(\mathrm{d}_{\mathrm{iL}}^{+}+\mathrm{d}_{\mathrm{iU}}^{-}\right)\left(1-\mathrm{z}_{\mathrm{i}}\right) \leq \mathrm{V}, \mathrm{i}=1,2,3 ; \mathrm{z}_{\mathrm{i}} \in\{0,1\}$, and the system constraints in $(23)$.

Now, for simplicity, introducing the equal weights $\mathrm{w}_{1}=\mathrm{w}_{2}=\mathrm{w}_{3}=1 / 3$ for goal achievement and taking $\lambda=0.5$, the problem is solved by employing the GA scheme, where the function $\mathrm{Z}$ defined in (25) appears here as the fitness function.

The resulting decision is obtained as:

$$
\left(\mathrm{x}_{1}, \mathrm{x}_{2}\right)=(0,2.0656)
$$

The achieved objective function values in the interval-valued form are:

$$
\mathrm{Z}_{1}=[0.99,3.34] \text { and } \mathrm{Z}_{2}=[0.14,0.45] \text {, }
$$


The result shows that a satisfactory decision is achieved here from the view point of distributing the proper decision powers to both the DMs in the decision making context.

Note: It may be noted that if the crisp coefficients, instead of interval coefficients, are involved with the objectives, then using the mid-point arithmetic rule [14] in IP, the problem can easily be solved under the framework of the proposed approach.

Again, it is worth mentioning that the computational complexity arising out of the fractional objectives [6] as well as the computational load involved with the use of conventional linearization approach [21] does not occur here due to the use of the proposed GA based solution approach.

\section{CONCLUSION}

The main advantage of using the proposed IP approach to the FBLPP is that the ambiguity of assigning the fixed objective values as necessarily introduced to the other MODM approaches (deterministic/ fuzzy) do not involve here due to consideration of the goals in the interval-valued form for their achievement. Here, on the basis of the needs and desires of the DMs, the objective values can be achieved within the specified intervals according to the given ranges of the input parameter values of the coefficients in the decision making environment. Further, the approach is flexible enough to set up the interval parameter values based on the needs of an organization in the hierarchical decision system. The proposed approach can be extended to MLPPs with multiplicity of objectives in a large hierarchical decision making organization, which is a problem for future study. However, it is expected that the proposed approach may open up many new looks into the field of practical hierarchical decision problems for sustainable growth of an organization in the current competitive world for survival.

\section{REFERENCES}

[1] Ignizio, J.P (1976) Goal Programming and Extensions, Lexington, Massachusetts, D.C. Health.

[2] Bard, J.F. \& Falk, J.E. (1982) "An explicit solution to multi-level programming problem", Computers and Operations Research, Vol. 9, pp.77-100.

[3] Bialas, W.F. \& Karwan, M.H. (1982) “On two level optimization”, IEEE Transactions on Automatic Control, Vol. 27, pp. 211-214.

[4] Candler, W. \& Townsley, R. (1982) “A linear two-level programming problem",Computers and Operations Research, Vol.9, pp.59-76.

[5] Bialas, W.F. \& Karwan, M.H. (1984) “Two level linear programming”, Management Sciences, Vol.30, pp. 1004-1020.

[6] Ludhandjula, M. K. (1984) "Fuzzy approaches for multiple objectives linear fractional optimization", Fuzzy Sets and Systems, Vol. 13, pp. 11-23.

[7] Zimmermann, H.-J. (1987) Fuzzy Sets, Decision Making and Expert Systems, Kluwer Academic Publisher, Boston, Dordrecht, Lancaster.

[8] Anandalingam, G. (1988) "A mathematical programming modelof decentralized multi-level system", Journal of Operational Research Society, Vol. 39, No.11, pp.1021-1033.

[9] Goldberg, D.E. (1989) Genetic Algorithms in Search, Optimization, and Machine Learning, AddisonWesley, Reading. MA.

[10] Inuiguchi, M. \& Kume, Y. (1991) "Goal Programming Problems with interval coefficients and target intervals”, European Journal of Operational Research, Vol.52, pp.345-360.

[11] Romero, C. (1991) Handbook of critical issues in goal programming, Pergamon Publ. Corp.

[12] Mathiew, R., Pittard, L. \& Anandalingam, G. (1994) "Genetic Algorithm based method for bilevel linear programming”, Recherch Ope'rationnelle / Operations Research, Vol. 28, No.1, pp. 1-21.

[13] Gen, M., Liu, B.\& Ida, K. (1996) "Evolution program for deterministic and stochastic optimizations", European Journal of Operations Research, Vol. 94, pp. 618-625, 1996.

[14] Moore, R.E. (1996) Interval Analysis, Prentice Hall, New Jersey. 
[15] Sakawa, M., Nishizaki, I. \& Hitaka, M. (1999) "Interactive fuzzy programming for multi-level 0-1 programming problems through genetic algorithms", European Journal of Operational Research, Vol. 114, pp.580-588.

[16] Sakawa, M., Nishizaki, I. \& Hitaka, M. (2001) "Interactive fuzzy programming for multi-level 0-1 programming problems with fuzzy parameters through genetic algorithms", Fuzzy Sets and Systems, Vol. 117, pp.95-111.

[17] Deb, K. (2002) Multi-objective Optimization using Evolutionary Algorithms, John Wiley \& Sons Ltd.

[18] Hejazi, S.R. , Memariani, A. , Jahanshahloo, G.\& Sepehri, M.M (2002) "Linear bilevel programming solution by genetic algorithm”, Computers and Operations Research, Vol. 29, pp.19131925.

[19] Liu, B. (2002) Theory and Practice of Uncertain Programming, 1st ed., Physica-Verlag, Heidelberg.

[20] Pal, B.B. \& Moitra, B. N. (2003) "Fuzzy goal programming procedure for solving quadratic bilevel programming problems", International Journal of Intelligent Systems, Vol.18 (5), pp. 529-540.

[21] Pal, B., Moitra, B. N. \& Maulik, U. (2003) "A Goal Programming Procedure for Fuzzy Multiobjective Linear Fractional Programming Problem”. Fuzzy Sets and Systems, Vol. 139, pp. 395 -405 .

[22] Pal, B. B. \& Pal, R. (2003) "A linear multilevel programming method based on fuzzy programming", Proceedings of APORS 2003, Vol. 1, pp.58-65.

[23] Maside, X., Lee, A.W. \& Charlesworth, B. (2004) "Selection on Codon Usage in Drosophila Americana", Current Biology, Vol. 14, pp.150-154.

[24] Biswas, A. \& Pal, B.B (2007) "Fuzzy goal programming procedure for multiobjective bilevel programming problems", International Journal of Computer, Mathematical Sciences and Appl., Vol. 1 , No. 1, pp. 87-98.

[25] Olivera, C. \& Antunes, C.H. (2007) "Multiple objective Linear Programming Models with Interval Coefficients - an illustrated overview", European Journal Of Operational Research, Vol. 181, pp. 1434-1463.

[26] Pal, B.B \& Gupta, S.S. (2008) "A Goal Programming approach for solving interval valued Multiobjective Fractional Programming Problems by using Genetic Algorithm”, Proceedings Of IEEE 10th colloquium and International Conference on Industrial and Information Science 2008 (ICIIS 2008), pp.1-6.

[27] Pal, B.B. \& Sen, S. (2008) “A Goal Programming Procedure for solving Interval valued Multiobjective Fractional Programming Problems”, Proceedings of Sixteenth Int. Conf. on Advanced Computing and Communication 2008 (ADCOM 2008), pp. 297-302.

[28] Yang, Z. \& Nielsen, R. (2008) "Mutation-Selection Models of Codon Substitution and Their Use to Estimate Selective Strengths on Codon Usage", Mol. Biol. Evol., Vol. 25(3), pp. 568-579.

[29] Pal, B.B. \& Gupta, S.S. (2009) “A Genetic Algorithm Based Fuzzy Goal Programming Approach for solving Fractional Bilevel Programming Problems", Proceedings of International Conference of Operations Research in Engineering and Management (ICOREM 2009), pp. 306-325.

[30] Pal, B.B., Chakraborti D. and Biswas, P, (2011) "Using Genetic Algorithm for Solving Linear Multilevel Programming Problems via Fuzzy Goal Programming", Communication in Computers and Information Science, CCIS 140, Springer-Verlag Berlin Heidelberg , pp. 79-88.

[31] Chakraborti, D. and Biswas, P. (2012), “An Application of Genetic Algorithm for Solving Academic Personnel Planning Problems in University Management System via Fuzzy Goal Programming with Penalty Functions", International Journal of Computer Applications, Vol. 38, No. 12, pp. 23-32. 